\title{
MENTAL FATIGUE DOES NOT AFFECT HEART RATE RECOVERY BUT IMPAIRS PERFORMANCE IN HANDBALL PLAYERS
}

\author{
FADIGA MENTAL NÃO ALTERA A RECUPERAÇÃO DA FREQUÊNCIA CARDÍACA, MAS AFETA O \\ DESEMPENHODE JOGADORES DE HANDEBOL
}

\section{FATIGA MENTAL NO VARÍA LA REPARACIÓN DE FRECUENCIA CARDIACA Y MUDA EL RENDIMIENTO ENBALONMANO}

Eduardo Macedo Penna ${ }^{1,2}$
(Physical Education Professional)
Edson Filho $^{3}$
(Physical Education Professional)
Bruno Teobaldo Campos ${ }^{1}$
(Physical Education Professional) $^{2}$
Daniel Alvarez Pires
(Physical Education Professional)
Fabio Yuzo Nakamura
(Physical Education Professional)
Thiago Teixeira Mendes 1,5
(Physical Education Professional)
Thiago Ribeiro Lopes ${ }^{6}$
(Physical Education Professional)
Mitchell Smith
(Physical Education Professional)
Luciano Sales Prado
(Physical Education Professional)

1. Universidade Federal de Minas Gerais (UFMG), Belo Horizonte, $M G$, Brazil.

2. Universidade Federal do Pará (UFPA), Castanhal, PA, Brazil.

3. Social Interaction and

Performance Science Laboratory, School of Psychology, University of Central Lancashire, Preston, United Kingdom.

4. James Cook University,

The College of Healthcare Sciences, Queensland, Australia.

5. Universidade Federal do Maranhão (UFMA); São Luís, MA, Brazil.

6. Olympic Training Center, São Paulo, SP, Brazil.

7. University of Newcastle, NSW, Australia.

\section{Correspondence:}

Escola de Educação Física da Universidade Federal do Pará, Campus Universitário de Castanhal, Av. Dos Universitários s/n, Jaderlânda, Castanhal, PA, Brazil. 68746-360.eduardomp@ufpa.br.

\begin{abstract}
Introduction: This study involved an analysis of the impact of mental fatigue on heart rate recovery (HRR), subjective measures of fatigue and intermittent running performance in handball players. Objective: This study was aimed at (1) examining the effects of an induced state of mental fatigue on the aerobic performance of handball players, as measured by the Yo-Yo IR1 test, and (2) exploring possible changes in heart rate regulation through HRR analysis. Methods: Twelve handball players (age: $17.50 \pm 3.63$ years; $5 \pm 2.2$ years of practice) undertook a Yo-Yo IR1 test on two occasions, separated by an interval of at least 72 hours. The Yo-Yo IR1 test was preceded by a 30-min treatment, consisting of the Stroop Color-Word Test, to induce mental fatigue. Participants in the control condition watched an emotionally neutral video. Results: Higher ratings of mental fatigue and mental effort following the Stroop Test were observed for the experimental group. No differences in motivation were observed between conditions. Moreover, the induction of mental fatigue impaired running performance and led to a higher RPE during the Yo-Yo IR1 test. Notwithstanding, no changes in HRR or blood lactate levels were observed across conditions. Conclusion: Altogether, these results suggest that mental fatigue impairs intermittent running performance, without affecting HRR values. Level of Evidence III; Case-Control study.
\end{abstract}

Keywords: Mental fatigue; Athletic performance; Exercise tolerance; Fatigue; Exercise test.

\section{RESUMO}

Introdução: Este estudo envolveu uma análise do impacto da fadiga mental sobre a recuperação da frequência cardiaca (RFC), medidas subjetivas de fadiga e desempenho de corrida intermitente em jogadores de handebol. Objetivo: Este estudo visou (1) examinar os efeitos de um estado induzido de fadiga mental no desempenho aeróbico dejogadores de handebol, medido pelo teste Yo-Yo IR1 e (2) explorar possíveis alterações na regulação da frequência cardíaca através da análise da RFC. Métodos: Doze jogadores de handebol (idade: 17,50 3,63 anos, $5 \pm 2,2$ anos de prática) realizaram um teste Yo-Yo IR1 em duas ocasiões, com pelo menos 72 horas de intervalo. O teste Yo-Yo IRI foi precedido por tratamento de 30 minutos que consistiu no teste Stroop Color-Word para induzir estado de fadiga mental. Os participantes na condição de controle assistiram a um vídeo emocionalmente neutro. Resultados: Foram observadas taxas mais elevadas de fadiga mental e esforço mental após o teste Stroop para o grupo experimental. Não foram observadas diferenças na motivação entre as condições. Além disso, a indução de fadiga mental prejudicou o desempenho de corrida e levou a maior PSE durante o teste Yo-Yo IR1. Não obstante, não foram observadas alterações na RFC nem nas concentrações de lactato sanguíneo entre as condições. Conclusão: Em conjunto, esses resultados sugerem que a fadiga mental afeta o desempenho de corrida intermitente, sem alterar os valores de RFC. Nível de Evidência III; Estudo de caso-controle.

Descritores: Fadiga mental; Desempenho atlético; Tolerância ao exercício; Fadiga; Teste de esforço.

\section{RESUMEN}

Introducción: En el presente estudio se analizó el impacto de la fatiga mental en la recuperación de la frecuencia cardíaca (RFC), las medidas subjetivas de fatiga y el rendimiento intermitente en atletas de handball. Objetivo: los objetivos de este estudio fueron (1) examinar los efectos de un estado inducido de fatiga mental en el rendimiento aeróbico de atletas de handball, medida por el Yo-Yo IR1, y (2) explorar las posibles alteraciones en la regulación de la frecuencia cardíaca a través del análisis RFC. Métodos: Doce atletas (edad: 17,50 $\pm 3,63$ años, $5 \pm 2,2$ años de práctica) realizaron un test Yo-Yo IRI en dos ocasiones, separados por un intervalo de al menos 72 horas. El test Yo-Yo IRI fue precedido por un tratamiento de 30 minutos, consistente en el Stroop Color-Word Test, para inducir un estado de fatiga mental. Los participantes en la condición de control asistieron un video emocionalmente neutro. Resultados: Se observaron altas percepciones de fatiga y esfuerzo mental después del test de Stroop para el grupo experimental. No se observaron diferencias de motivación entre las condiciones. Además, la inducción de fatiga mental perjudicó el 
desempeño de carrera y llevó a un mayor PSE durante el test Yo-Yo IR1. No obstante, no se observaron alteraciones en la RFC y en las concentraciones de lactato sanguíneo entre las condiciones. Conclusión: En conjunto, estos resultados sugieren que la fatiga mental afecta el rendimiento intermitente de la carrera, sin alterar los valores de FCR. Nivel de Evidencia III; Estudio de caso-control.

Descriptores: Fatiga Mental; Rendimiento Atlético; Tolerancia al ejercicio; Fatiga; Test de Esfuerzo.

\section{INTRODUCTION}

Handball is an intermittent sport, with specific requirements according to the players' positions. ${ }^{1,2}$ To this extent, mental fatigue has been described as an intervening factor affecting athletic performance. ${ }^{3}$ As such, advancing research about fatigue in handball is paramount, as mental fatigue can impair information processing and decision-making, ultimately impairing performance.

Mental fatigue is conceptualized as a psychobiological state induced by sustained periods of demanding cognitive activity and characterized by feelings of tiredness and lack of energy. ${ }^{4,5}$ Within sports, previous research has shown that a 30-minute cognitive task impairs subsequent physical, technical, and decision-making performance among soccer players., ${ }^{6,7}$ However, to the best of our knowledge, no research has examined the influence of mental fatigue on performance in handball players.

In endurance sports, 5,8 an induced state of mental fatigue has been shown to reduce performance. These negative effects on performance have been attributed to higher ratings of perceived exertion (RPE). In other words, when mentally fatigued, individuals perceive the same given stimulus as more effortful than in control situations,, 10 thus reducing one's exercise tolerance.

Although mental fatigue impairs physical performance, mental fatigue has not been linked to changes in physiological variables, such as heart rate and blood lactate concentrations in intermittent activities. ${ }^{5,9}$ Previous studies have shown that mental fatigue can impair muscular recovery ${ }^{11}$ and alter the autonomic regulation of heart rate. ${ }^{12,13}$ However, as far as we are concerned, no previous study has tested whether mental fatigue alters heart rate recovery (HRR) after different exercise conditions.

The analysis of HRR is relevant to studies in mental fatigue for various reasons. First, HRR is a non-invasive marker of autonomic control of the heart that results from a coordinated interaction between sympathetic withdrawal and parasympathetic re-activation. ${ }^{14}$ Second, in sport and exercise settings, HRR is a reliable marker of athletic performance ${ }^{15}$ and Negative changes in HRR are indicative of insufficient recovery which, in turn, leads to decreased athletic performance. ${ }^{16,17}$

In light of the aforementioned, the purposes of this study were to (1) examine the effects of an induced state of mental fatigue on aerobic performance of handball athletes, as measured by the Yo-Yo IR1, and (2) explore possible alterations in heart rate regulation through HRR analysis. It was hypothesized that mental fatigue would impair physical performance, and alter the cardiac autonomic regulation of $\mathrm{HR}$, respectively.

\section{METHODS}

Twelve regional-level handball players from an amateur club (age: $17.50 \pm 3.63$ years old; $5 \pm 2.2$ years of practice) participated in this randomized, cross-over investigation. As inclusion criteria, the participants should be affiliated to the state and/or national handball federation and should not present any injury in the last month. At the time of the study, all participants were competing in either state or national level events and trained an average of 6 hours per week. Prior to the study, the participants signed an informed consent form outlining the study procedures which, in turn, were approved by leading authors'University Ethics Committee (project number 55286716.0.0000.5149).

\section{Experimental Overview}

Participants were instructed to maintain regular sleep patterns and consumption of caffeine. Furthermore, the participants were asked to avoid any vigorous exercise at least $24 \mathrm{~h}$ and take a regular meal at least $2 \mathrm{~h}$ before the testing sessions. The testing sessions were separated by a minimum of $72 \mathrm{~h}$.

Upon arrival for testing, participants received a standard explanation of the procedures. Then, the participants received a standard explanation about the 6-20 RPE scale and were instructed to drink $500 \mathrm{~mL}$ of water. Subsequently, they were directed to a quiet room where the pre-assessment of mental fatigue was administered by (1) asking the participants to complete a Visual Analogue Scale (VAS); and (2) measuring five minutes of resting heart rate (HR) using a chest strap connected to a Polar V800 watch. Next, the control or mental fatigue treatment were conducted. Immediately following the treatment, the VAS scale was again completed. The participants were then directed to a handball court, whereby they completed the Yo-Yo Intermittent Recovery Test, level 1 (Yo-Yo IR1). No verbal encouragement was given to the participants during the tests. RPE was measured after every 40-m stage. After the test, the subjective assessments (i.e., RPE, Mental Fatigue and Mental Effort) were repeated and heart rate was recorded again during for 5 minutes.

Mental fatigue was induced using a 30-min paper version of a modified Stroop Color Word task. This test has been used in recent studies involving mental fatigue in sporting contexts., ${ }^{9,18}$. During the test, the participants verbalized the color of words (red, blue, green and yellow) printed in a random order. The correct answer corresponded to the ink color of the word. However, if the ink color of the word was "red", the correct answer was the word itself rather than the color of the word. A member of the research team monitored the participants' verbal responses. Upon making a mistake, the participants were instructed to restart the current line of words. Participants were instructed to respond correctly to as many words as possible. The control condition involved watching a 30-min emotionally neutral video involving the history of world aviation.

\section{Perceptual Subjective Measures}

Subjective ratings of mental fatigue, mental effort and motivation were recorded pre-treatment, post-treatment and post-running test using 100-mm VAS as a manipulation check. Motivation was measured only post-treatment, with respect to the upcoming running trial. This scale has been used in mental fatigue studies in sport and exercise. ${ }^{9,18} \mathrm{To}$ analyze the VAS scales, a ruler was used to measure the distance between the initial mark and the point marked by the participant. Scores were reported as arbitrary units (AU).

\section{Objective Performance Measures}

The Yo-Yo IR1 test was performed according to the procedures suggested by. ${ }^{19}$ Test reliability was established in a previous study. ${ }^{20}$ This test was validated to measure the aerobic performance in young 
handball players. ${ }^{21}$ The Yo-Yo IR1 test consists of repeated $2 \times 20-m$ runs back and forth between the starting, turning, and finishing line at a progressively increased speed controlled by audio bleeps from a tape recorder. Between each running bout, the participants were given a 10-s active rest period, consisting of $2 \times 5 \mathrm{~m}$ of walking. When the subjects twice have failed to reach the finishing line in time, the distance covered was recorded as the final test result.

Blood lactate was measured as a manipulation check for the Yo-Yo IR1. Five microliters were taken from the fingertip before and immediately after the Yo-Yo IR1 test. Blood samples were stored at $-80^{\circ} \mathrm{C}$ until analysis was performed and concentrations were determined using an electroenzymatic method (YSL 1500 SPORT, Yellow Springs, OH, EUA).

For the HRR measurement, conducted immediately following the Yo-Yo IR1, the participants remained lying down on the floor for five minutes, with a normal breathing rate, in silence and with no body movements. A chest strap (Polar ${ }^{\circledR}$ H7. Kempele, Finland) connected to a recording watch (Polar ${ }^{\circledR}$ V800, Kempele, Finland) was used to continuously recorded R-R intervals during this period (Task Force, 1996). All irregular heartbeats were replaced with interpolated adjacent R-R interval values using the Polar Software (Pro Trainer 5, Polar Electro, Finland). HR at the end of tests (HRend) was defined as the HR registered at the exact moment in which the test ended. HRR assessment included the raw $H R$ data, and was defined as the $H R$ value at a given point within the recovery period (i.e., every 30 seconds). Relative HRR was defined as the difference between $H R$ registered at the end of exercise (HRend) and every 30 s thereafter (i.e., $\Delta 30 \mathrm{~s}, \Delta 60 \mathrm{~s}, \Delta 90 \mathrm{~s}, \Delta 120 \mathrm{~s}, \Delta 150 \mathrm{~s}, \Delta 180 \mathrm{~s}, \Delta 210 \mathrm{~s}$, $\Delta 240 \mathrm{~s}, \Delta 270 \mathrm{~s}$ and $\Delta 300 \mathrm{~s}$ ). This method of HRR analysis is in congruent with previous published empirical research guidelines in sport and exercise, ${ }^{15,22}$ and mirrored the protocol used in previous study. ${ }^{23}$

\section{Statistical Analysis}

Data were initially examined for normality (Shapiro-Wilk test) and homogeneity (Levene's test). A paired Student's t-test was performed to compare mean data (collected at a single point) between the experimental trials. A series of two-way repeated measures ANOVAs followed by Tukey's post hoc tests were used to compare data between experimental trials over distance, or at different moments (PRE-TREAT, POST-TREAT and POST-RUN). A series of Wilcoxon Rank test (non-parametric tests) were used to compare RPE data between trials. Additionally, Cohen's $\mathrm{d}$ effect-size (ES) estimates were calculated to assess the magnitude of difference between the experimental conditions. ES was calculated through mean differences (Cohen, 1988) and was considered trivial (ES < 0.2), small (ES 0.2 - 0.6), medium (ES 0.6-1.2) or large (ES $\geq 1.2){ }^{24}$ All analyses were performed in the Sigma Plot 11 statistical package. The significance level was set at $p \leq 0.05$.

\section{RESULTS}

\section{Perceptual Subjective Measures}

A significant condition $x$ time interaction was found for subjective reports of mental fatigue ( $F=6.05 ; p<0.01$; power $=0.77$ ). Follow-up tests revealed no between-condition differences in mental fatigue at PRE-TREAT ( $p=0.76$; $E S=0.13$ ). No differences were found over time analysis for control manipulation, between PRE-TREAT vs. POST-TREAT ( $p=0.95 ; \mathrm{ES}=0.11)$ and POST-TREAT vs. POST-RUN $(p=0.14 ; \mathrm{ES}=0.57) . \mathrm{In}$ contrast, following the Stroop Test, mental fatigue increased $(p<0.001$; $\mathrm{ES}=1.36)$, and remained higher at POST-RUN ( $p<0.01$; ES $=1.13)$, compared to PRE-TREAT. A significant effect between experimental manipulations was found for POST-TREAT only ( $p<0.01$; ES $=1.32$; see Figure 1-A).

Mental effort was higher than the control treatment after the Stroop Test ( $p<0.001$; ES $=2.80$ ), but after exercise was not found different between conditions ( $p=0.80$; $E S=0.08$ ) (Figure 1-B). At POST-TREAT, motivation was not different between trials $(p=0.28$; power $=0.08$; $E S=0.29$ ) (Figure 1-C).

A significant difference among the participants' RPE responses for the experimental condition was observed $(Z=-4.84 ; p>0.001)$ and RPE was higher in the mental fatigue condition over 80 - $200 \mathrm{~m}$ of Yo-Yo IR1, and reached similar values close to the 40-m mark at the end of both conditions (Figure 2-A).

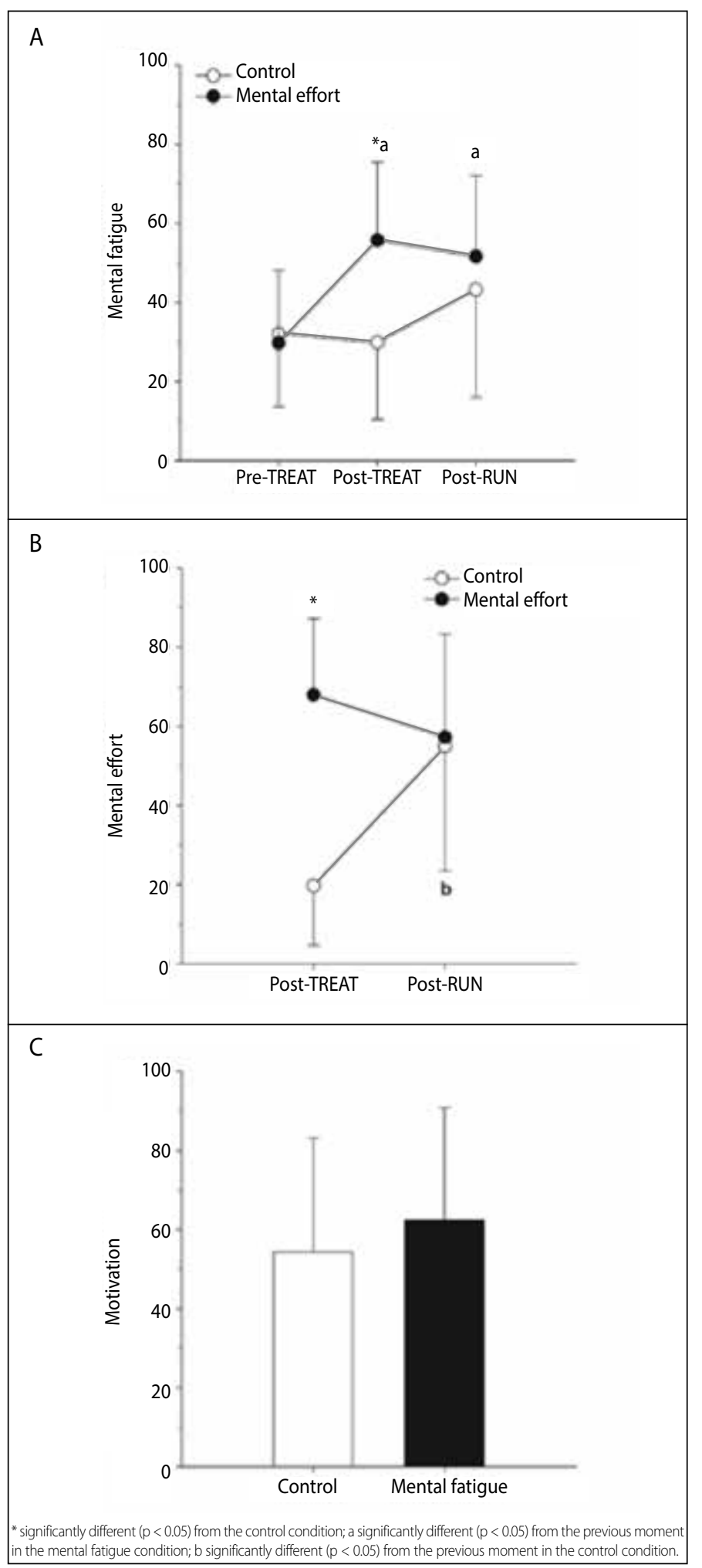

Figure 1. Subjective measures of mental fatigue (A) before (PRE-TREAT), after the Stroop test or control manipulation (POST-TREAT) and at post- running (POST-RUN). Mental effort (B) after the Stroop test or control manipulation (POST-TREAT) and at postrunning (Post-RUN). Motivation (C) before the running time-trial for both conditions. 


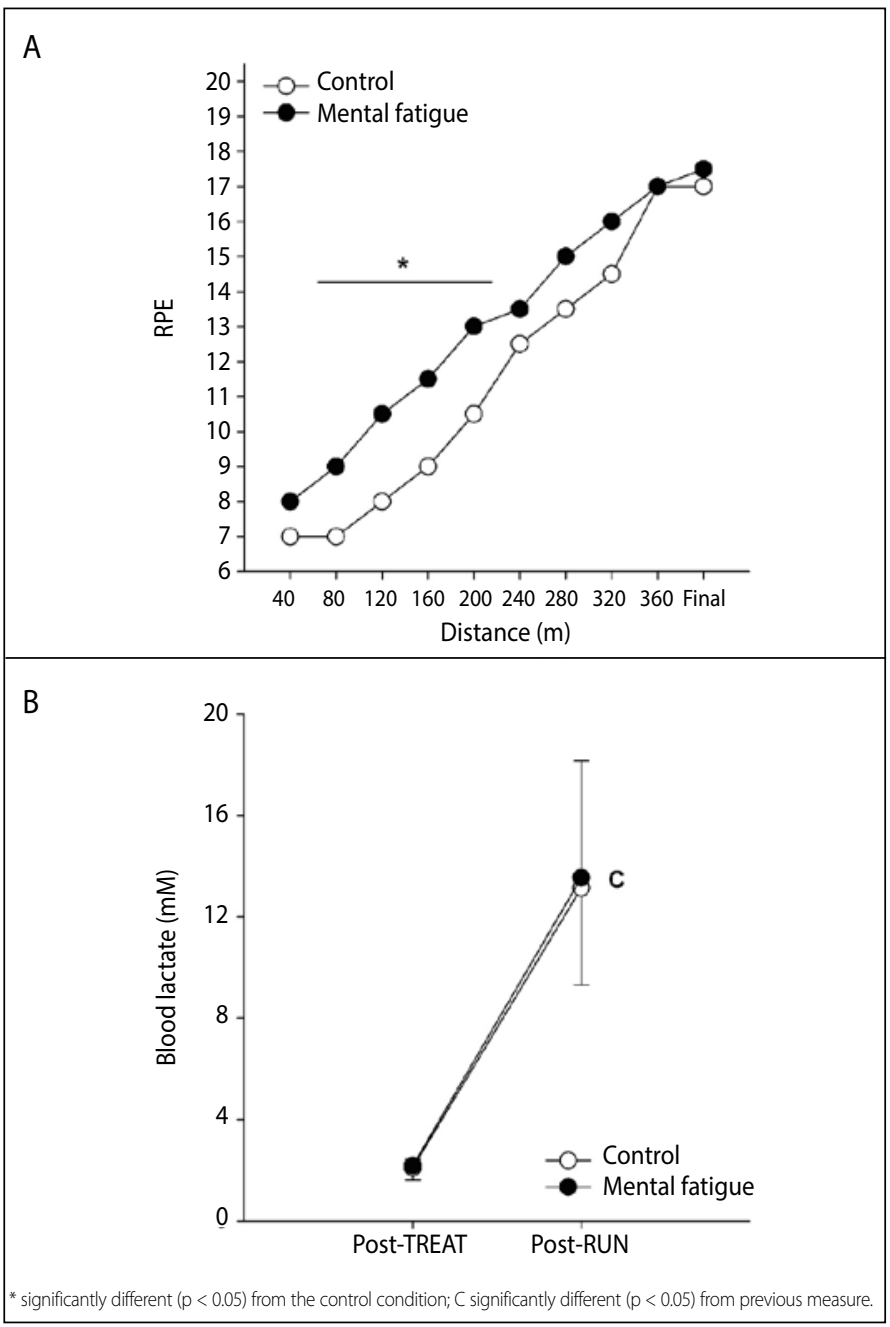

Figure 2. Rate of perceived exertion (A) and blood lactate values (B) during running the Yo-Yo IR1 time-trial for both experimental conditions.

\section{Objective Performance Measures}

The mental fatigue manipulation reduced the total distance covered during the Yo-Yo IR1 $(7.9 \pm 10.4 \% ; p<0.05$; power $=0.68$; $\mathrm{ES}=0.40$; see Figure 3-A). Overall, 10 of the 12 handball players ran a shorter distance in YO-YO IR1 after being subjected to the Stroop task (Figure 3-B).

Blood lactate levels increased after running Yo-YO IR1 at POST-RUN $(p<0.01 ; E S=4.95)$. However, blood lactate responses only showed a significant effect for the time of analysis; i.e., pre-to post $(F=113.89$; $p>0.001$; power $=1.00)$. No significant differences between experimental conditions was observed $(F=0.15 ; p=0.71$; power $=0.05)$.

No significant differences in HRR were observed between conditions (Figure 4).

\section{DISCUSSION}

In the present study, we tested the hypotheses that a mental fatigue state would: (1) impair aerobic performance; and (2) alter HRR values after a Yo-Yo IR1 test among handball athletes. Our findings confirmed the first hypothesis only. Specifically, mentally fatigued subjects showed an impaired running performance without any concomitant changes in their HRR or blood lactate concentrations. Collectively, these findings corroborate previous studies on the relationship between mental fatigue and physical performance. ${ }^{8,9,18}$

Regarding the subjective perceptual measures analyzed, our findings indicate that a 30 min Stroop task induced a mental fatigue state (Figure 1-A). Specifically, perception of mental fatigue, as measured by the VAS,

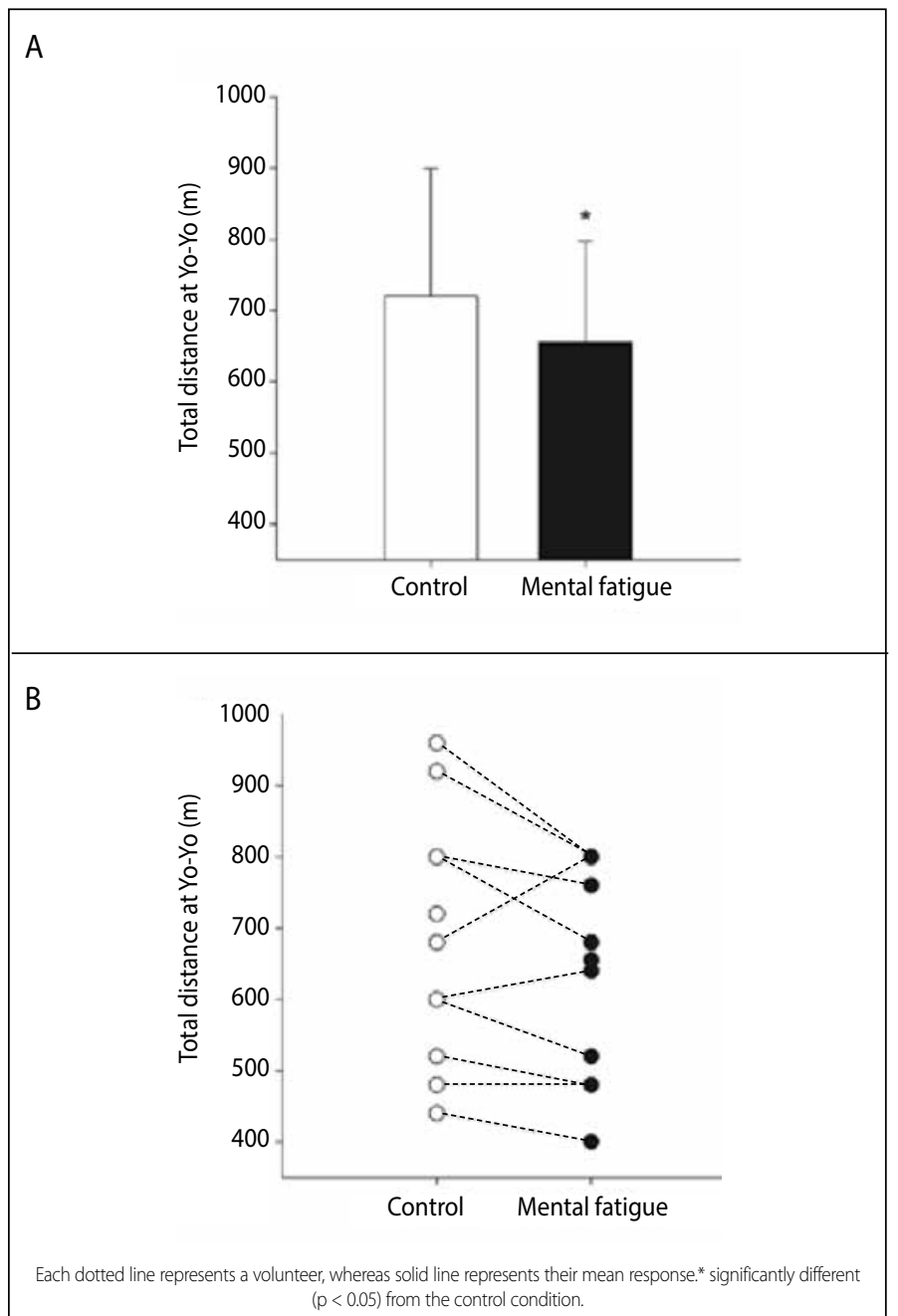

Figure 3. Mean total distances (A) and individual distances (B) covered at Yo-Yo IR1 time-trial at the two-experimental condition (i.e., control and mental fatigue trials).

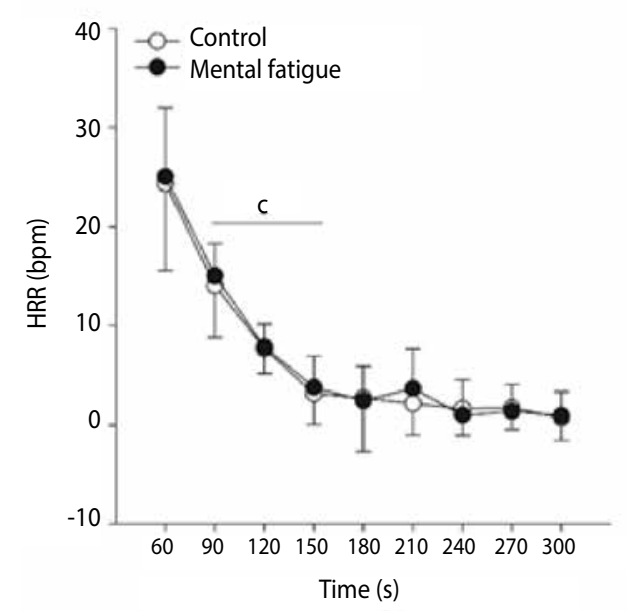

Figure 4. Heart Rate Recovery values after the Yo-Yo IR1 for both experimental conditions.

was higher in the mentally fatiguing condition when compared to control. The same pattern was observed for perceived mental effort (Figure 1-B). Together, these findings indicate that the participants in the mentally fatiguing condition started the running test under a higher cognitive stress which, in turn, might explain their decreased physical performance. Importantly, decreased physical performance in the experimental condition was not due to motivation, as perceived motivation scores 
did not differ between conditions (Figure 1-C). In this regard, mental fatigue has been associated with impairment in other affective factors, such as efficiency and availability of resources, but has not been shown to affect motivation ${ }^{25}$.

The results concerning RPE revealed a higher perception of effort in the mentally fatiguing condition (Figure 2-A). This result corroborates other investigations that have shown an increased RPE trend in a mentally fatigued condition given two identical exercise protocols. ${ }^{8}$ These findings demonstrate that cognitively demanding activity before exercise is harmful to performance, especially when effort regulation is required, since no influence was identified in all-out tests when individuals were mentally fatigued. ${ }^{26}$

The analysis of the Yo-Yo IR1 running test results demonstrated that physical performance in handball athletes was negatively affected by the mental fatigue (Figure 2). These results corroborate previous findings in intermittent exercise in general, ${ }^{9}$ and interactive team sports in particular. ${ }^{18}$ In the case of handball, which is a sport that requires intermittent efforts (physical demand), multiple tactical decisions and prolonged sustained attention (mental demand), long term-training of both demands could increase resilience to mental fatigue. ${ }^{27}$ In the present study, this putative resilience effect to mental fatigue was not identified; the participants were sensitive to mental fatigue (Figure 1-A), which in turn led to impaired physical performance (Figure 2). This contrast is likely due to differences in performance level of the athletes.

Regarding the physiological markers of performance, no differences between conditions were observed in blood lactate concentration (Figure 2-B) and in the HRR (Figure 4). Hence, similar to the observed by ${ }_{1}^{9}$ the impaired intermittent running performance of handball players presented by the mentally fatigued condition cannot be explained by any cardiometabolic alteration. Again, only perceptual changes related to the effort employed in the Yo-Yo IR1 running test were observed.

It follows that our hypothesis that mental fatigue alters the vagal tonus and promotes sympathetic hyperactivity was not supported. It is well established that the HRR is modulated mainly by parasympathetic reactivation and sympathetic withdrawal after the cessation of cardiovascular exercise. ${ }^{28}$ Despite some studies showing that mental fatigue protocols can lead to an altered autonomic activity (measured by heart rate variability), ${ }^{12}$ it seems that a 30 min Stroop color test is not enough to alter this autonomic balance after an intermittent running test using HRR as a parameter. This difference is not marginal as HRR and heart rate variability are related to separate mechanisms within the autonomic system. Heart Rate Variability reflects the parasympathetic modulation, whereas HRR is preferentially related to vagal tonus. ${ }^{22}$ Hence, the present study suggests that mental fatigue does not influence recovery of the vagal tonus after intermittent exercise, which thereby can present different kinetics when compared to continuous exercise. ${ }^{29}$

\section{CONCLUSIONS}

The present study demonstrates that induction of mental fatigue impaired physical performance in handball players subjected to a Yo-Yo IR1 test. During the mentally fatigued condition, athletes presented a higher RPE, and ran shorter distances than in the control condition. No changes in HRR were observed between conditions. In practice, our results suggest the importance of avoiding any activity involving higher cognitive demands prior to important training sessions and matches due to their potential harmful effects on exercise endurance.

All authors declare no potential conflict of interest related to this article.

AUTHORS' CONTRIBUTIONS: Each author made significant individual contributions to this manuscript. EMP (0000-0003-0058-7967), BTC (0000-0002-1816-8325), EF (00000002-8548-4651) and LSP (0000-0001-7554-1926) were the main contributors in the drafting of the manuscript. EMP, BTC and DAP (0000-0003-2163-5606) collected data, FYZ (0000-0002-5336-3652), TTM (0000-0003-1644-4020) and TRL (0000-0003-2586-3948) organized the data and performed the statistical analysis. EMP, BTC, EF, DAP, FYN, TTM, TRL, MRS (0000-0002-8168-5405) and LSP carried out a literature review and wrote the manuscript. EMP, BTC and MRS revised and formatted the final version of the manuscript. *ORCID (Open Researcher and Contributor ID).

\section{REFERENCES}

1. Haugen T, Tonessen E, Seiler S. Physical and physiological characteristics of male handball players: Influence of playing position and competitive level. J Sports Med Phys Fitness. 2016;56(1-2):19-26.

2. Karcher C, Buchheit M. On-Court Demands of Elite Handball, with Special Reference to Playing Positions. Sports Med. 2014;44(6):797-814.

3. Van Cutsem J, Marcora S, De Pauw K, Bailey S, Meeusen R, Roelands B. The Effects of Mental Fatigue on Physical Performance: A Systematic Review. Sports Med. 2017;47(8):1569-88.

4. Boksem MA, Tops M. Mental fatigue: Costs and benefits. Brain Res Rev. 2008;59(1):125-39.

5. Marcora SM, Staiano W, Manning V. Mental fatigue impairs physical performance in humans. J Appl Physiol (1985). 2009;106(3):857-64.

6. Smith MR, Zeuwts L, Lenoir M, Hens N, De Jong LM, Coutts AJ. Mental fatigue impairs soccer-specific decision-making skill. J Sports Sci. 2016;34(14):1297-304.

7. Badin OO, Smith MR, Conte D, Coutts AJ. Mental Fatigue Impairs Technical Performance in Small-Sided Soccer Games. Int J Sports Physiol Perform. 2016;11(8):1100-5.

8. Penna EM, Filho E, Wanner SP, Campos BT, Quinan GR, Mendes TT, Smith MR, Prado LS. Mental fatigue impairs physical performance in young swimmers. Pediatr Exerc Sci. 2018;30(2):208-15.

9. Smith MR, Marcora SM, Coutts AJ. Mental fatigue impairs intermittent running performance. Med Sci Sports Exerc. 2015;47(8):1682-90.

10. Brownsberger J, Edwards A, Crowther R, Cottrell D. Impact of mental fatigue on self-paced exercise. Int J Sports Med. 2013;34(12):1029-36.

11. Mehta RK, Agnew MJ. Influence of mental workload on muscle endurance, fatigue, and recovery during intermittent static work. Eur J Appl Physiol. 2012;112(8):2891-902.

12. Mizuno K, Tanaka M, Yamaguti K, Kajimoto $O$, Kuratsune $H$, Watanabe $Y$. Mental fatigue caused by prolonged cognitive load associated with sympathetic hyperactivity. Behav Brain Funct. 2011;7:17.

13. Tanaka M, Mizuno K, Tajima S, Sasabe T, Watanabe Y. Central nervous system fatigue alters autonomic nerve activity. Life Sci. 2009;84(7-8):235-9.

14. Carnethon MR, Jacobs DR Jr, Sidney S, Sternfeld B, Gidding SS, Shoushtari C, et al. A longitudinal study of physical activity and heart rate recovery: CARDIA, 1987-1993. Med Sci Sports Exerc. 2005;37(4):606-12.

15. Buchheit M. Monitoring training status with HR measures: do all roads lead to Rome? Front Physiol. 2014:5:5-73.
16. Bellenger CR, Fuller JT, Thomson RL, Davison K, Robertson EY, Buckley JD. Monitoring Athletic Training Status Through Autonomic Heart Rate Regulation : A Systematic Review and Meta-Analysis. Sport Med. 2016;46(10):1461-86.

17. Lazic JS, Dekleva M, Soldatovic I, Leischik R, Suzic S, Radovanovic D, et al. Heart rate recovery in elite athletes: the impact of age and exercise capacity. Clin Physiol Funct Imaging. 2017;37(2):117-23.

18. Smith MR, Coutts AJ, Merlini M, Deprez D, Lenoir M, Marcora SM. Mental fatigue impairs soccer-specific physical and technical performance. Med Sci Sports Exerc. 2016;48(2):267-76.

19. Bangsbo J, laia FM, Krustrup P. The Yo-Yo Intermittent Recovery Test: a useful tool for evaluation of physical performance in intermittent sports. Sports Med. 2008;38(1):37-51.

20. Krustrup P, Mohr M, Amstrup T, Rysgaard T, Johansen J, Steensberg A, et al. The Yo-Yo intermittent recovery test: Physiological response, reliability, and validity. Med Sci Sports Exerc. 2003;35(4):697-705.

21. Souhail H, Castagna C, Mohamed HY, Younes H, Chamari K. Direct validity of the Yo-Yo intermittent recovery test in young team handball players. J Strength Cond Res. 2010;24(2):465-70.

22. Buchheit M, Papelier Y, Laursen PB, Ahmaidi S. Noninvasive assessment of cardiac parasympathetic function: postexercise heart rate recovery or heart rate variability? Am J Physiol Hear Circ Physiol. 2007;293(1):H8-10.

23. Del Rosso S, Nakamura FY, Boullosa DA. Heart Rate Recovery After Aerobic and Anaerobic Tests : Is There an Influence of Anaerobic Speed Reserve? J Sports Sci. 2017;35(9):820-7.

24. Hopkins WG, Marshall SW, Batterham AM, Hanin J. Progressive statistics for studies in sports medicine and exercise science. Med Sci Sports Exerc. 2009;41(1):3-13.

25. Gergelyfi M, Jacob B, Olivier E, Zénon A. Dissociation between mental fatigue and motivational state during prolonged mental activity. Front Behav Neurosci. 2015;9:176.

26. Martin K, Thompson KG, Keegan R, Ball N, Rattray B. Mental fatigue does not affect maximal anaerobic exercise performance. Eur J Appl Physiol. 2015;115(4):715-25.

27. Martin K, Staiano W, Menasp P, Hennessey T, Marcora S, Keegan R, et al. Superior Inhibitory Control and Resistance to Mental Fatigue in Professional Road Cyclists. PLoS One. 2016;11(7):e0159907.

28. Borresen J, Lambert MI. Autonomic Control of Heart Rate during and after Exercise: measurements and implications for monitoring training status. Sport Med. 2008;38(8):633-46.

29. Watson AM, Brickson SL, Prawda ER, Sanfilipo JL. Short-term heart rate recovery is related to aerobic fitness in elite intermittent sport athletes. J Strength Cond Res. 2017;31(4):1055-61. 